stimulating effect. Barcroft's work suggests that it may well be of the greatest value where the normal mechapism is failing and the organism possibly having to rely on a more primitive one. If this is so, it is but one more example of the clinical acumen of our forefathers which has been discredited not because it was wrong but because its mode of action was misunderstood, or because the conditions of the physiological experiment were such as to prevent its giving a correct answer. "The proper study of mankind is man," and though cats and dogs are useful, they can never replace the acid test of human experiment. I suggest that those with the requisite opportunities might try the application of Barcroft's work in the way I have indicated.I am, etc.,

$$
\text { Winsford, Cheshire }
$$

W. N. LEAK.

\section{Artificial Insemination}

SIR,-Dr. Eustace Chesser's letter (May 24, p. 738) is a valuable contribution towards a correct assessment of the problem of heterogeneous insemination. He admits having dealt with cases of homologous and heterogeneous insemination and now condemns the latter.

Recently in Newcastle we were addressed on the legal problems of this matter, which was dealt with from every aspect. We were informed that the donor should be a married man with one or two children and of proved health. I made, inter alia, the following remarks: "Artificial insemination of cattle is justifiable, as it involves no ethical problem. The majority of the males are castrated and it is only reasonable for commercial purposes that the remainder may distribute their favours, as after all we eat the progeny. I have never done homologous insemination, but I would consider it ethically correct to aid fertilization if, for example, coitus was impossible owing to vaginismus or some other abnormality. Heterogeneous insemination brings in a special factor which revolts one. What type of individual can the donor be who hawks his seminal fluid round the countryside at so much per c.c.?"

Judging by the way a large mixed audience received my remarks, from personal talks, letters, and phone messages, I am sure that the bulk of them felt as I did. Dr. Chesser's letter strikes me as being written by one with deep conviction.I am, etc.,

Newcastle-upon-Tyne.

FARQuHar MurRay.

\section{Infant Deaths}

SIR,-With reference to Dr. S. Waddy's letter on infant deaths (May 24, p. 737), in which he draws attention to the danger of toro great a weight of blankets on an infant's cot, a recent necropsy which I performed may be of interest.

A healthy baby aged four weeks was found "panting for breath" one morning in its cot and died before the arrival of a doctor. A necropsy revealed all the signs of asphyxia in an otherwise normal infant. At the subsequent inquest the mother was asked about the clothing and bedclothes of the child. The disclosure that on the warmest night of this year the unfortunate babe was bedecked in (1) a woollen vest, (2) a woollen coat, (3) a woollen night-dress, and (4) woollen bootees, and had as covering four wonllen blankets and an eiderdown-the blankets being "well tucked in "-left no doubt as to the cause of the asphyxia. Comment is unnecessary.-I am, etc.,

Northampton.

RUbY O. STTERN.

\section{Keeping Mother and Baby Together}

SIR,- We have read with much interest and pleasure the paper by Prof. J. C. Spence on "The Care of Children in Hospital" (Jan. 25, p. 125) and note that he approves of the method we have been using as much as possible for the last 20 years and exclusively for the past 6 years in a small special hospitalnamely, encouraging every mother to nurse her own baby (vide B.M.J., Feb. 3, 1945, p. 159, and Sept. 7, 1946, p. 337). Given the right conditions the system works well and gives excellent results. Babies want constant attention and "mothering"; to break the bond between mother and baby is to introduce an unnecessary hurdle into treatment which may spell the difference between success and failure. We have noted also the objections of Drs. W. E. Crosbie and J. Lorber (Feb. 15, p. 266) to the mother-and-baby system of nursing.
We in our work are of course frequently up against the same trouble of a mother finding it difficult to leave her home and family. But here is where grandma or auntie will nearly always step into the breach ; someone can invariably be found to look after the home. The only insuperable difficulty is when the mother herself is ill and possibly in hospital. In such a case we get a "foster mother," if possible again an aunt or grandmother or other relative, and it is astonishing how soon the foster mother and baby get fond of each other; and it is this bond of fondness which is so valuable to the baby patient in its time of trial.

Again we would emphasize it is of no use putting a mother with her baby in a ward. They must have a little room to themselves which is their own private room, and under these conditions the classical description by Prof. Spence of a children's ward commencing "The room is vast" is never applicable. The simple fact is that there are not enough nurses and not enough time for baby patients to be given all the attention they require. -We are, etc.,

Wellington, N.Z.

\section{H. P. Pickerill.} CeCILy Pickerill.

\section{Health of Children Attending Day Nurseries}

SiR,- - The observations made by Dr. Margaret E. McLaughlin as stated in her preamble (May 3, p. 591) cannot lead to definite conclusions, owing to the impossibility of assessing the relative effects of economic and environmental factors on such a survey, unless the obvious course is taken of studying these vital social factors simultaneously with the purely pathological one attempted. Out of many points which require further investigation that reading "The inference that there were no significant physical differences at the start of nursery life between day-nursery children and those living at home may reasonably be assumed to apply also to the present survey" requires more evidence than that afforded by examinations by a variety of observers on 290 children "scattered all over the country" and then statistically compared to the 4,297 children in the major groups studied.

From my experience of the basis of admission to day nurseries priority is invariably reserved for mothers forced to work ; the reasons leading to this necessity operate before and after pregnancy; therefore their level of nutrition and take-up of extra rations and vitamin supplements (owing to lack of free time and financial stringency) is lower than that of the normal home-living mother. One would not expect the babies born to this group to have the optimum physique and resistance obtainable. Day nursery care would have to overcome this initial inferiority before any reasonable comparison could be made between them and other groups. If the statement $I$ refer to can be scientifically proved I suggest the whole of our nutrition policy for expectant mothers must be based on a fallacy.

This report emphasizes the vital importance of good staffing and management and should reinforce the struggle to raise the standard of training in child welfare to a national university level, as advocated by the report issued in 1946 by the National Society of Children's Nurseries. These "extensions of the home" must and can be made safe in order that they may assist the solution of a multitude of acute social problems-to quote a few, the work of the Marriage Guidance Council-to enable the mother to meet the psychological needs of toddler, schoolchild, and adolescent, with the obvious bearing on the problems of juvenile delinquency, promiscuity, and venereal disease ; and to enable the mother to obtain the maximum benefit from the provision of the National Health Service for treatment for herself and young family. For all of these I welcome the suggestion that the attendance of children "for two or three half days a week is a question worthy of investigation."- I am, etc.,

Farnham, Surrey.

NORA M. JOHNS.

\section{Food Poisoning}

SIR,-I was much interested to read the paper in your number of April 5 (p. 442) about an epidemic of food poisoning traced to staphylococcal contamination of sandwiches. It recalled to me a case that was clinically typical Asiatic cholera that occurred in a country practice in the Orange Free State in the year 1922. I published it in the (since defunct) South African 
Medical Record, 1922, 20, 209, and asked if any similar cases had been observed in other places, there being an epidemic of "paracholera" reported about that time. Nobody took any notice of my short paper and I was disappointed not to hear of any similar cases.

As I said, the case was typically Asiatic cholera, with very violent vomiting, diarrhoea, cramps, and collapse, with ricewater stools, but bacteriologically no organism was found but pure streptococcus. I wonder if such symptoms have often been associated with pure streptococcal infection. It is very interesting to note the great difference from the clinical manifestations of staphylococcal infection as reported in the paper recently published.-I am, etc.,

Durban.

C. Lundie.

\section{Undernutrition}

SiR,-The letter from Dr. Martin Herford (May 17, p. 696) is extremely valuable and demonstrates the real existence of subclinical undernutrition, which is not by any means fully appreciated.

For years before this latest of wars I fed my stomach, as both it and $I$ thought, satisfactorily, and we both thrived. Then came the war-meals now only three courses! We-my stomach and I-assimilated these new conditions protestingly and gradually and now after all these years we have adjusted curselves. But has my body benefited or worsened under the difference? Do I suffer from lack of calories and vitamins, or am I benefited from a compulsory deprivation of a surplus of purins and fats? Shades of Nat Gubbins dialling "Tum"! $I$ only know that I get more indigestion than I used to do and that I tire more easily. Therefore I believe that my diet as a hard-working man is inadequate and that the old scale of large and more varied meals suited me best, though $I$ doubt if Tum would now digest them-such is habit and the adaptation of the human body. Saliva flows at the thought of a pre-war meal ; but does carcinoma lurk in the background?-I am, etc.,

•London, S.W.1.

Desmond MacManus.

\section{Planning for Health}

SIR,-I ask for space for a matter of importance in the world of positive health and to air a flouted first principle in the pursuit of planning. In 1932 I selected a camping ground for boys at Snettisham Beach, Norfolk. It had much to recommend it. 'It was far from houses, yet within a mile of a station; it had a good water supply, was within the "dry belt," was the nearest seaside place to some of the East Midland towns ; the bathing and sailing were fairly safe, and at low tide there were miles of sands, a gloriously healthy arena for games, cockling, and other noble sports. For seven years many hundreds of boys from all over the country enjoyed free camping there and during the war half the camp, about nine acres, was taken over by some 800 Americans.

After the war the camp was handed over to the Workers' Travel Association, a non-profit-making concern with an excellent record, which provides holidays for workers. With increasing holidays with pay this body has an extra job of work to do and it was thought that they would utilize this camp to the best advantage. When, however, they applied to the local planning committee for permission to raise the necessary buildings, our modest ones having been levelled by the Allies, they met with a refusal :

"The grounds for my committee's decision are to prevent danger or injury to health arising and further detriment to the neighbourhood, in view of the low-lying nature of the land which is liable to
flood."

If this ill-conditioned sentence means anything it means that the land is liable to flood and that the sewage from the camp might spread round and infect the neighbours. But there are none, and in any case the slope of drainage from the camp is down to marsh land where there is no house for miles. Moreover the camp land has never been flooded within living memory, nor could it be unless eight miles of marsh land lying 20 feet below were flooded first. That sentence was written in January of this year; then came the floods over much of the country and county, but this land was not flooded nor was the marsh land below.
In these circumstances I wrote and asked the local planning committee the names of their health experts, these men who were so demonstrably wrong and who in my view used the excuse of health to prevent workers gaining health. The reply was: ". . I I am not, at the present time, in a position to supply you with the information you request or to offer a further opinion on the matter."

Now this may be a local affair, but I suggest that a principle of first importance is involved: planners and experts must not be anonymous, otherwise we have no guarantee of their ability or that they are not stupid or self-interested or both.-I am, etc.,

$$
\text { Rye, Sussex. }
$$$$
\text { C. G. Learoyd. }
$$

\section{Entry to Dartmouth}

SIR,-I had hoped that someone more learned than I would have raised this matter of the change of the age of entrance to Dartmouth from $13 \frac{1}{2}$ to 16 . I have had considerable experience of schoolboys of all ages and classes. It seems physiologically unsound to transfer a boy to the strict discipline of the R.N.C. in the middle of adolescence. The present method whereby a boy enters the Navy at the onset of adolescence or at the end, or at least when it is stabilized, is sound, and the results are admittedly good, very good. At present a number of boys are taken from elementary schools at the lower age, with, I understand, satisfactory results. It is hard to see what advantage is to be gained by removing a boy at this most unstable period into a strange milieu.-I am, etc.,

Clifton, Bristol.

R. G. Cookson.

\section{Tobacco}

SIR,- In your recent leading article (April 26, p. 570) on this burning (!) topic you. twice referred to tobacco smoking as a habit. This is a common but, in my view, a serious error. Tobacco smoking is not a habit but a drug addiction, a disease. Untruthfulness is an outstanding symptom of the drug addictions. It is well recognized in morphinism and cocainism, but it is not generally realized that, on matters concerning tobacco, tobacco smokers are exceedingly untruthful. The untruth that smoking is a habit is perhaps the most important. Other fundamental untruths circulated by smokers are that smoking is a vice and tobacco a luxury, and I yould be grateful if you would allow me space in which to "nail" them.

The essence of a habit is that it is acquired by repetition, and references to tobacco smoking as a habit carry the implication that the repetitive act of administering tobacco smoke-puffing -is the essence of tobacco smoking, not intoxication with nicotine, carbon monoxide, and pyridine bases-the main constituents of tobacco smoke. ${ }^{1}$ Even in bringing about the administration of tobacco smoke habit is much less important than craving for tobacco, as anyone cured of tobacco addiction -knows. Is opium smoking also a habit, and intoxication with the alkaloids of opium of secondary importance? Clearly the essence of tobacco smoking is the tobacco and not the smoking. Satisfaction can be obtained from chewing it, from snuff taking. and from the administration of nicotine. ${ }^{2}$ The majority of diseases are intoxications of one kind or another and the intermittent intoxication induced by tobacco smoking must surely be accounted a disease. The terms "drug habit" and "smoking habit" ought also, in my view, to be forsworn.

The untruth that smoking is a vice is somewhat nearer the truth. Vice or moral deterioration is an essential symptom of drug addiction. It is merely, however, a symptom (secondary to craving); the disease is drug addiction. It is revealed, in the case of tobacco smoking, in frequent non-observance and sometimes obliteration of non-smoking notices, in abuse of those who ask that these be observed, in untruthfulness about tobacco, and in the frequent failure of smokers to honour their obligations. An example of this, much to the point, is the failure of our tobacco-addicted profession to prevent this serious disease, which is no more difficult to prevent than addiction to opium. Tobacco is treated in this country not as a toxic drug of addiction, which it is, but as a luxury, which it is not. It is not included under the provisions of the Dangerous Drugs Act; it is sold to the public in almost unlimited quantities, and its 